\title{
Impacts of agricultural activities on soil phosphorus biogeochemical transformations
}

\author{
Chunhao Gu, ${ }^{1 *}$ Chongyang Li,,${ }^{1}$ Yongfeng Hu, ${ }^{2}$ \\ ANDREW J. MARGENOT ${ }^{1}$ \\ ${ }^{1}$ University of Illinois at Urbana-Champaign, IL, USA \\ (*Correspondence: chunhao@illinois.edu, \\ margenot@illinois.edu; cyfli@ucdavis.edu) \\ ${ }^{2}$ Canadian Light Source, University of Saskatchewan, \\ Saskatoon, Canada (Yongfeng.Hu@lightsource.ca)
}

Agriculture is thought to be the driving force of profound anthropogenic alteration of global phosphorus (P) cycle. A comprehensive understanding of how agriculture changes $\mathrm{P}$ biogeochemical transformation would entail better environmental and agricultural management of the finite reserve of $\mathrm{P}$. This study evaluated long-term (centennial) impacts of agricultural activities on $\mathrm{P}$ biogeochemical transformations using soils from the Morrow Plots at the University of Illinois, the second oldest long-term agricultural plots in the word established in 1865 and situated in a region of intensive agriculture, the US Corn Belt. Sampled in 2020, these plots provide a 155 year factorial experiment of 2 crop rotations of Continuous Corn (CC) versus Corn-Oats-Alfalfa $(\mathrm{COA}) \times 3$ fertilization regimes of manure, NPK, and no fertilization. Two restored ( $>30 \mathrm{y}$ ) native land uses of grassland and forest sites were sampled for comparison to approximate non-agricultural land use, on the same soil type (loess-derived Aqiuc Argiudoll). Soils were analysed by P K edge X-ray absorption near-edge structure (XANES) spectroscopy.

Phosphorus speciation in agricultural soils was dominated by $\mathrm{Fe}$-bound and/or Al-bound forms (( $\mathrm{Fe}+\mathrm{Al})-\mathrm{P}, 55.0-$ $83.8 \%)$ with varying proportions of organic $\mathrm{P}\left(\mathrm{P}_{\mathrm{o}}\right)$ and $\mathrm{Ca}-$ bound $\mathrm{P}(\mathrm{Ca}-\mathrm{P})$ that reflected interactions of crop rotation and fertilization regimes. For both $\mathrm{COA}$ and $\mathrm{CC}$, manured soils had up to $50 \%$ greater Mechlich-3 $\mathrm{P}$ than without fertilization. Regardless of crop rotation, both NPK fertilized and unfertilized agricultural soils had similar $\mathrm{P}_{\mathrm{o}}$ and Ca-P proportions but had less $\mathrm{P}_{\mathrm{o}}$ and greater Ca-P than manured soils. Greater differences occurred between agriculturally managed soils (Morrow Plots) than the reference (restored) native land uses. Overall, soil Ca-P decreased in the order of Forest (36.2\%), Prairie (24.9\%), and agricultural (2.7 - 19.5\%) soils. Results suggest that, on the centennial-scale, agriculture led to depletion of $\mathrm{Ca}-\mathrm{P}$ regardless of diverse crop rotations and inputs of $\mathrm{P}$ and other elements. By virtue of its longevity and the complementarity of $\mathrm{P}$ characterization approaches used, this study affords unique insights to long-term impacts of agricultural management on soil $\mathrm{P}$ cycling in one of the most intensified agricultural regions of the world. 